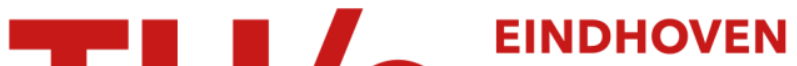 UNIVERSITY OF TECHNOLOGY
}

\section{Permeability thickening fluids for improved secondary oil recovery}

Citation for published version (APA):

Golombok, M., \& Wijst, R. P. M. (2013). Permeability thickening fluids for improved secondary oil recovery. Journal of Petroleum Exploration and Production Technology, 110(22), 22-26.

https://doi.org/10.1016/j.petrol.2013.08.040

DOI:

10.1016/j.petrol.2013.08.040

Document status and date:

Published: 01/01/2013

\section{Document Version:}

Publisher's PDF, also known as Version of Record (includes final page, issue and volume numbers)

\section{Please check the document version of this publication:}

- A submitted manuscript is the version of the article upon submission and before peer-review. There can be important differences between the submitted version and the official published version of record. People interested in the research are advised to contact the author for the final version of the publication, or visit the $\mathrm{DOI}$ to the publisher's website.

- The final author version and the galley proof are versions of the publication after peer review.

- The final published version features the final layout of the paper including the volume, issue and page numbers.

Link to publication

\section{General rights}

Copyright and moral rights for the publications made accessible in the public portal are retained by the authors and/or other copyright owners and it is a condition of accessing publications that users recognise and abide by the legal requirements associated with these rights.

- Users may download and print one copy of any publication from the public portal for the purpose of private study or research.

- You may not further distribute the material or use it for any profit-making activity or commercial gain

- You may freely distribute the URL identifying the publication in the public portal.

If the publication is distributed under the terms of Article 25fa of the Dutch Copyright Act, indicated by the "Taverne" license above, please follow below link for the End User Agreement:

www.tue.nl/taverne

Take down policy

If you believe that this document breaches copyright please contact us at:

openaccess@tue.nl

providing details and we will investigate your claim. 


\title{
Permeability thickening fluids for improved secondary oil recovery
}

\author{
Michael Golombok*,1, Roy van der Wijst ${ }^{2}$ \\ Shell Global Solutions bv, Kessler Park 1, 2288GS Rijswijk, The Netherlands
}

\section{A R T I C L E I N F O}

\section{Article history:}

Received 10 December 2012

Accepted 26 August 2013

Available online 5 September 2013

\section{Keywords:}

permeability

water flooding

secondary oil recovery

shear induced structures

\begin{abstract}
A B S T R A C T
Waterflooding is limited by zones of spatially varying permeability which cause channelling. More crude oil could be produced by a more uniform water/brine front across layers of different permeabilities. Novel non-polymeric water additives $(\mathrm{CTAB}+\mathrm{NaSal}$ in brine) are used to selectively slow down flow of water in high permeability zones. In order to isolate rheological effects from rock fluid interactions, we have carried out experiments on inert glass cores. A monotonic increase of viscosity as function of permeability is observed for the range $45-2200 \mathrm{mD}$ (covering typical reservoir ranges). This effect can be referred to as permeability thickening. This result opens up the possibility of tunable fluid engineering for any given permeability distribution of reservoirs. Low additive concentrations ( $<1000$ ppm) yield insitu permeability dependent viscosities up to 40 times that of brine. Flow in high permeability zones is retarded more than in low permeability ones which results in typically 15-36\% extra sweep area based on single phase experiments.
\end{abstract}

(c) 2013 Elsevier B.V. All rights reserved.

\section{Introduction}

Only about one-third of oil present is on average extracted from a reservoir. The main reason for this is the inability to control the breakthrough of water in high permeability regions (Dowd, 1974). Water finds a path of low resistance from the injector to the producer well after which no more oil can be swept out by water injection (Fig. 1a). The flow of water can be controlled by addition of viscosity modifying additives such as hydropolymerised polyacryl amides (HPAM) (Delshad et al., 2008). However these materials only have the property of being highly injectable and providing viscous enhancement in the whole reservoir. It would be better to have an additive which automatically retards water flow in just the high permeability zones with no, or at least less slowing down, in the low permeability zones (Fig. 1b). The property that needs to be modified is thus the injected water viscosity. This paper is about a novel class of additives which have the potential to give the required viscosity properties.

Viscosity modifying additives are usually characterised by their Couette rheometer response. The viscosity is measured as a function of a single shear rate which can be varied to give a viscosity vs. shear curve. Materials exhibiting increasing or decreasing viscosity with shear rate materials are called shear

\footnotetext{
* Corresponding author. Tel.: + 3170447 2327; fax: + 31704472332.

E-mail address: michael.golombok@shell.com (M. Golombok).

${ }^{1}$ Also with Faculty of Mechanical Engineering, Technische Universiteit Eindhoven, Den Dolech 2, 5600 MB Eindhoven, The Netherlands.

${ }^{2}$ Currently with ExxonMobil Chemical Holland B.V., Merwedeweg 21, 3198 LH Europoort Rotterdam, The Netherlands.
}

thickeners and shear thinners respectively. Theoretically a shear thickener (Jones, 1980) would overcome the problem of water breakthrough except that it would be uninjectable because it has the highest viscosity under these conditions. Other materials such as HPAM are principally shear thinning but have a restricted region over which they show desirable shear thickening behaviour (Delshad et al., 2008).

In recent years attention has focused on the application of viscoelastic surfactants in solution with counterions. A combination which has been widely studied and which shows the greatest viscosity contrasts are the materials used in this study: cetyl ammonium bromide (CTAB) and sodium salicylate (NaSal) respectively. Like all surfactants, above a threshold concentration in solution, spherical micelles are formed. In the presence of counterions, wormlike micelles form on the micron scale which induce unusual rheological behaviour. Under flow conditions, shear induced structures (SIS) are generated and these have also been characterised initially by Couette flow (Wang et al., 1994; Cressely and Hartmann, 1998). There are few studies of these micellar rheology modifiers in porous media. Siriwatwechakul (2005) reported the behaviour of shear induced structures at $50 \mathrm{mM}$ concentration in thin membrane filters. Gonzalez et al. (2005) and Rojas et al. (2008) have studied rheological effects of SIS materials in monodisperse glass bead beds. Golombok et al. (2008) demonstrated selective velocity retardation in sandstones. Subsequently it was shown (Smeets and Golombok, 2010) that there is an advantageous effect resulting from selective retention of CTAB in the reservoir rock. It has also been demonstrated that even after adsorption and prior to CTAB breakthrough, the selective retardation effects are maintained (Spain et al., 2009), which suggests 
that adsorption on clays would not be a problem. Such adsorption has also been observed by Howard and Craig (2009) in their surface studies of adsorption on silica wafers. While these, like the surfaces in this study, are hydrophilic, the authors also made the observation that for hydrophobic surfaces the surfactants will form tail bound monolayers. This suggests the behaviour to be expected in the as yet unexplored area of application on oil wet rocks such as many carbonates. Wormlike micelles are also seen as more interesting than polyacryl amides because they do not shear degrade (Awang et al., 2012). A number of applications have been considered (Ezrahi et al., 2006) but these are usually in more open media: there have been studies for different regular microflow structures such as cylinder arrays (Moss and Rothstein, 2010), capillary channels (Yamamoto et al., 2008) and a microfluidic channel with structured obstacles (Cheung et al., 2012).

The problem in applying any viscous additives is that flow in a reservoir is not determined by shear rate but rather by local variations in the bulk quantity permeability. What is therefore required is the viscosity as a function of permeability rather than shear. Whereas a Couette cell measurement has a single applied shear rate at any moment which can be controlled, this is not the case for permeable flow where there is a variation in shear through the pore. From a scientific viewpoint, Darcy's law as such is only applicable to Newtonian fluids. When measuring an "apparent" viscosity, then even for the single phase discussed here, it is better to use a fluid resistance factor in the

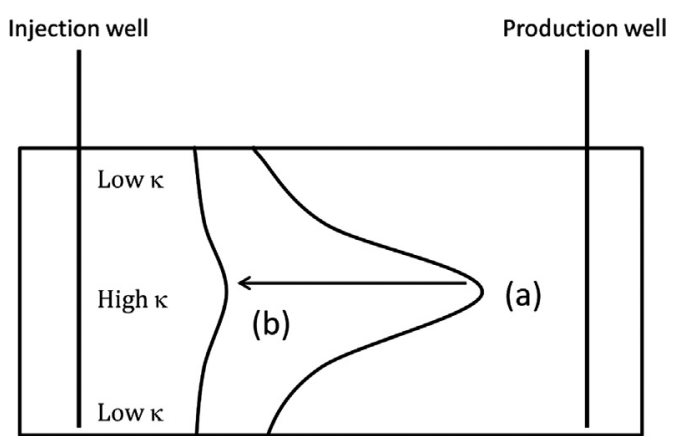

Fig. 1. Schematic of water breakthrough in a high permeability "streak" in secondary flooding. (a) Normal brine profile and (b) modified profile with additive.
Darcy equation

$u=\frac{\kappa}{R} \frac{\Delta p}{\Delta x}$

where $u$ is the Darcy velocity, $\kappa$ is the permeability and $\Delta p$ is the pressure drop over flow length $\Delta x$. Usually, the fluid resistance coefficient (written here as $R$ ) is identified with the fluid viscosity $\mu$. When one considers the factors which make a porous medium more complex than capillaries i.e. continuously varying widths, distribution of pore sizes, tortuosity, surface interactions, wetting etc. then it becomes clear why the macroscopic bulk Darcy derived viscosity will always be different from the microscopic Couette value. In fact the fluid resistance can be attributed to a number of components:

$R=R_{\mathrm{vis}}+R_{\mathrm{el}}+R_{\mathrm{p}}$

where $R_{\mathrm{vis}}$ is the shear viscosity derived from a Couette cell, $R_{\mathrm{el}}$ is an elongational viscosity component which is absent in Couette flow and $R_{\mathrm{p}}$ an elastic component associated with continual changes in pore dimensions. Gonzalez et al. (2005) and Rojas et al. (2008) developed this procedure to give an expression for the total resistance in a structured porous medium where the permeability consists of a purely geometric packing factor:

$\frac{\mathrm{R}}{\mu_{0}}=\frac{\kappa}{\mu_{0} u} \frac{\Delta p}{\Delta x}$

$\mu_{0}$ is the viscosity of the base solvent (i.e. water or brine) and $u$ the Darcy velocity. They stated that if shear flow dominates the behaviour of the solutions in porous media at low Reynolds number (which is the case in core samples in this study), $R$ is proportional to the total viscosity. This corresponds to an apparent viscosity for the porous media flow which can be calculated. These studies used stacked microspheres of much higher permeability range than those applicable to reservoir rocks where the range of interest is around ca. $20-2000 \mathrm{mD}$. In this study however, we apply $\mathrm{CTAB} / \mathrm{NaSal}$ mixtures to monodisperse media in the permeability range of interest to oil reservoirs. This enables us to get a measure of fluid resistance i.e. effective viscosity as a function of permeability. Previous work has characterised viscosity additives in terms of response to shear. In this work we demonstrate for the first time, resistance to permeable flow ("apparent" viscosity) as

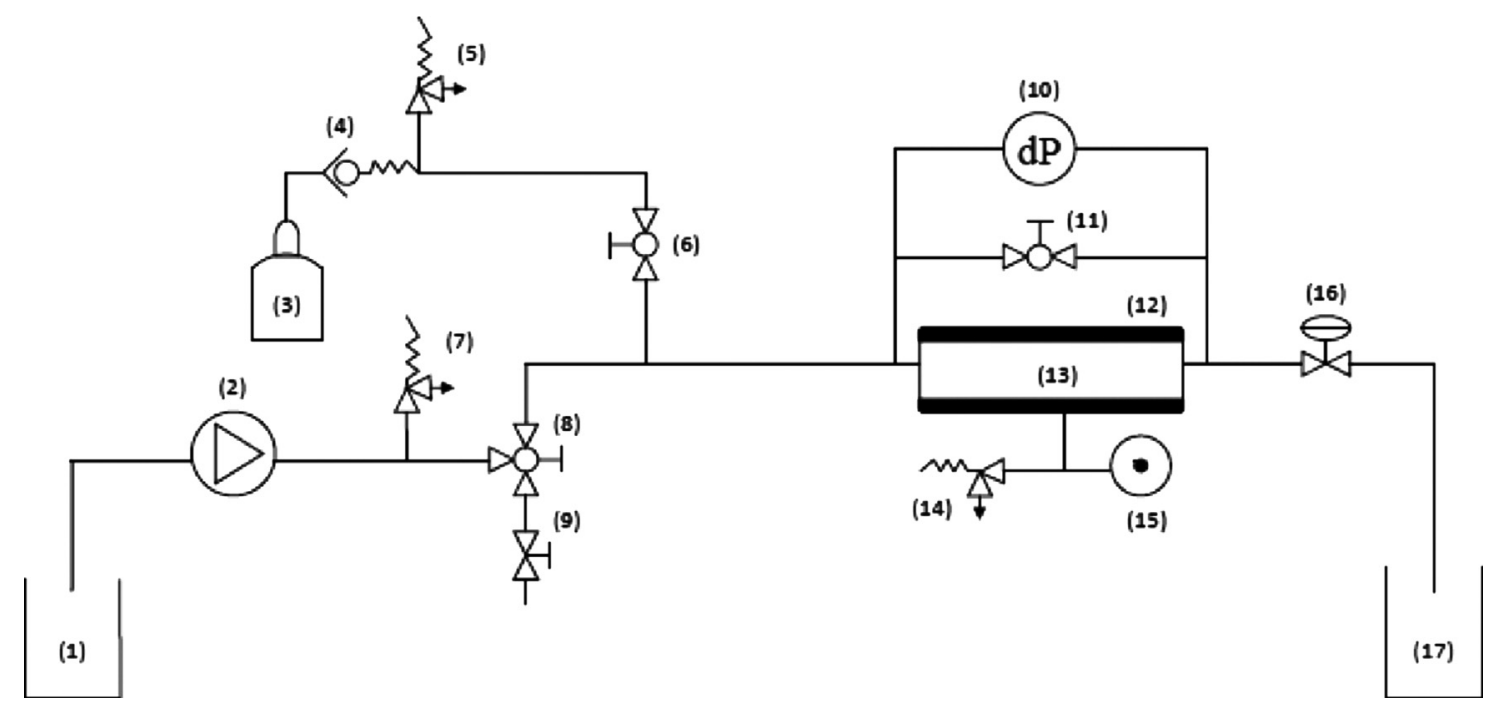

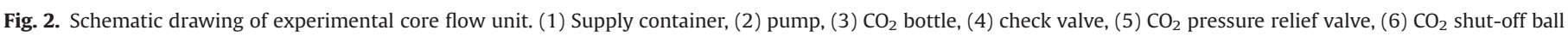

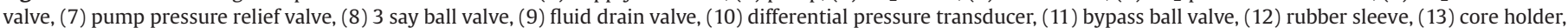
(14) sleeve pressure relief valve, (15) compressed air source, (16) back pressure regulator, and (17) effluent container. 
a function of permeability. This provides a method to "tune" viscous response to a spatial permeability distribution.

\section{Experiments}

\subsection{Core flow}

Fluid is pumped through a cylindrical sample of porous material - the core. A pressure difference and flow rate are recorded when a test fluid is flowed through the core sample. Flow resistance effects can be determined by calculating an apparent viscosity based on the recorded value for the flow rate and pressure difference over the core as described above (Fig. 2). The fluid is pumped by a Quizix QX 6000 HC pump through the core into the effluent container. The flow rate of the injected fluid is measured at the pump outlet and the pressure drop over the core is measured by a differential pressure transducer with connection to the upstream and downstream side of the core holder. The core is wrapped in a rubber sleeve and placed in a sealed and pressurised core holder. It is held on both sides by static pistons. The outlet pressure is ambient atmospheric pressure so that the only function of the pumps is to provide axial flow with a pressure drop to an outlet at 1 bar. The entry side piston creates a uniform fluid profile. Water or gas is used to provide radial pressure on the sample to prevent axially injected fluid from flowing radially and axially between core and rubber sleeve. The pressure drop is measured with a Rosemount 3051CD4 differential pressure transducer. The digitally controlled Quizix pumps in the setup could be used for either constant flow or a pulseless constant pressure control.

\subsection{Porous media}

Core samples are cylindrical segments of fused glass with length $40 \mathrm{~mm}$ and diameter $25.4 \mathrm{~mm}$. These are made from borosilicate sintered glass. The main advantage of working with glass core samples is that it provides a uniform permeability and is more inert than rock. The sintered glass cores were obtained from Robu Glasfilter Geraete GmbH. Different permeability classes of core are made by sintering glass extrudate segments of varying diameter. The permeability of each sample is calibrated by a brine test. Table 1 summarises data on the glass core along with the measured brine permeabilities.

\subsection{Fluids}

Throughout this study we denote by "SIS material" a combination of cetyl trimethyl ammonium bromide $-\mathrm{C}_{19} \mathrm{H}_{42} \mathrm{~N}$ Br (CTAB) and sodium salicylate $-\mathrm{Na}_{7} \mathrm{H}_{5} \mathrm{O}_{3}$ (NaSal) in various concentrations dissolved in a synthetic brine consisting of $3 \% \mathrm{w} / \mathrm{w} \mathrm{NaCl}$ in demineralised water. The shear induced structure fluids were made from equimolar concentrations of the chemicals CTAB and NaSal. CTAB of synthetic grade purity ( $>97 \%$ ) was obtained from Merck Schuchardt OHG and NaSal of reagent grade ( $>99.5 \%$ ) from Sigma Aldrich. The formation of links between the CTAB and NaSal

Table 1

Manufacturer's specifications and brine permeabilities measured for this study.

\begin{tabular}{llcr}
\hline Class description & $\begin{array}{l}\text { Porosity } \\
(\%)\end{array}$ & $\begin{array}{l}\text { Pore size } \\
(\boldsymbol{\mu} \mathbf{m})\end{array}$ & $\begin{array}{r}\text { Perm } \\
(\mathbf{m D})\end{array}$ \\
\hline P3 & 41 & $10-40$ & 45 \\
P4 & 42 & $6-10$ & 95 \\
P45 & 45 & $2-6$ & 395 \\
P5 & 48 & $0.5-2$ & 2200 \\
\hline
\end{tabular}

can occur at a range of concentrations and ratios of the components. In this study we confine ourselves to equimolar mixtures as these were previously shown to have optimal performance in reservoir rock samples (Smeets and Golombok, 2010).

\subsection{Procedure}

After placing the core holder in the setup, the system is flushed with $\mathrm{CO}_{2}$ in order to remove the air. Subsequently brine is injected. During any measurement, effluent is collected in a separate container for disposal. The remaining $\mathrm{CO}_{2}$ dissolves in the brine and is flushed out of the system. This ensures that there is no $\mathrm{CO}_{2}$ left in the system when the CTAB/NaSal solution is injected. After brine injection, then an SIS solution is injected at the same pressure drop. The flow falls rapidly but recovers fully when we switch back to the aqueous base fluid (i.e. water or brine). In real reservoir rock samples such as sandstones, clay swelling means that the water permeability is lower than the brine permeability. In the fused glass cores used in this study, the difference between brine and distilled water was barely measureable. This confirms the relative chemical inertness of the glass cores compared to rock samples and enables us to focus on rheological responses.

\section{Results}

The first step is to determine a suitable concentration range of SIS components for study of effects over the full range of core permeabilities (see Table 1). The aim is to retard flow selectively in the most permeable zone. Accordingly the $2200 \mathrm{mD}$ sample was used to evaluate the response at different equimolar concentrations of SIS in brine (Fig. 3). At $1 \mathrm{mM}$ concentration there is very little effect whereas at $2 \mathrm{mM}$ there is far too strong an effect for our experimental purposes. Even at high pressures the $2 \mathrm{mM}$ only produces low flow - and this is for the most permeable core in the study. A $1.5 \mathrm{mM}$ solution in brine demonstrates retardation over an acceptable range of pressures and flow rates and is chosen as the standard for this study.

The $1.5 \mathrm{mM}$ SIS solution was now injected in a variety of cores at varying pressures and the flow response measured. The $45 \mathrm{mD}$ and $95 \mathrm{mD}$ core samples show a rather linear response to an increase in flow rate with a low effective viscosity. The $395 \mathrm{mD}$ and $2200 \mathrm{mD}$ core samples show a clear non-linear response with lower slopes showing increasing viscosity at higher flow rates. Using the procedure described above (Eq. (1)) we derive the effective viscosities at either constant pressure drop or constant velocity. Fig. 4a shows viscosity as a function of pressure drop. At any fixed pressure drop the viscosity is seen to be higher at higher permeabilities. For each permeability, the viscosity increases to a maximum and decreases again. These pressure gradients are

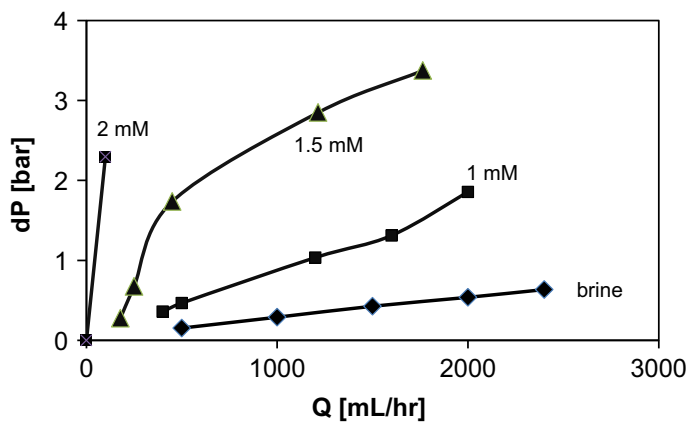

Fig. 3. Flow and associated pressure in a $2200 \mathrm{mD}$ glass core of $4 \mathrm{~cm}$ length and $25 \mathrm{~mm}$ diameter. The fluids are brine and also three different equimolar concentrations of CTAB and NaSal. 
a

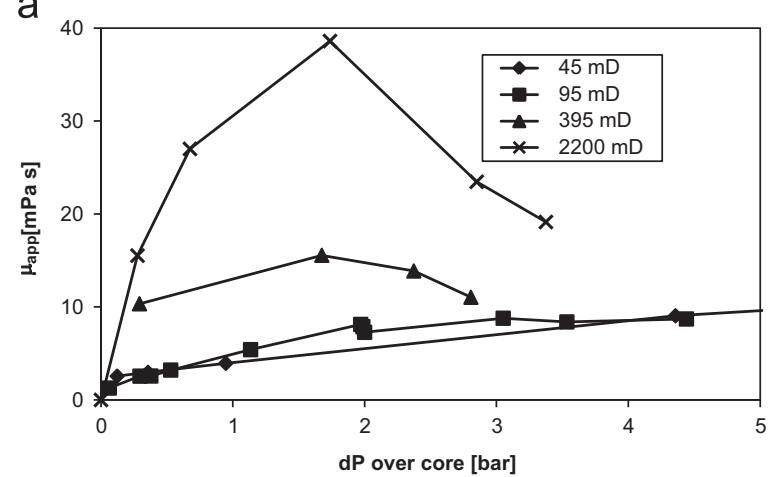

b

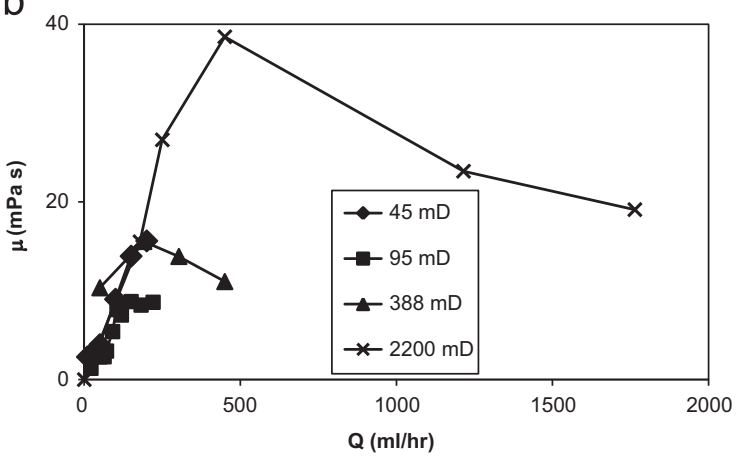

Fig. 4. Effective viscosity as a function of (a) pressure and (b) flow rate for four different permeability cores (see Table 1 ). The SIS solution was $1.5 \mathrm{mM}$ equimolar CTAB and NaSal.

considerably above those associated with oil recovery so we confine our attention to the lower range. The maximum viscosity is observed for the $2200 \mathrm{mD}$ core sample at approximately 40 times the value of its base fluid viscosity ( $1 \mathrm{mPa} \mathrm{s}$ ) according to Fig. 4a. For the $395 \mathrm{mD}$ core sample a maximum viscosity is observed at $15 \mathrm{mPa}$.

Fig. 4b shows the behaviour of viscosity as a function of the flow rate. Although shown here for completeness, for the lower permeabilities only a small range of flows at the lower end could be achieved and the viscosities are all close in value to each other for different permeabilities. This is typically used to compare fluid resistance of additives at a reference velocity (e.g. $1 \mathrm{ft} /$ day equivalent to $6.5 \mathrm{ml} / \mathrm{h}$ on this plot). However we question the applicability of " $1 \mathrm{ft} /$ day" for anything else rather than lab reference experiments. Although flow at a production well may be controlled, it is impossible to set a reference velocity deep in the reservoir. Ultimately in application, a pressure difference is applied between injector and producer and the flow profile which results is a function of the spatial distribution of permeability in the subsurface. The correct reference for typical permeabilities is thus a constant pressure drop. We sample the viscosity at a fixed pressure drop. Fig. 5 shows the viscosity as a function of permeability for a fixed pressure drop of $100 \mathrm{mbar} / \mathrm{m}$. A monotonic increase in viscosity as a function of permeability is observed. The apparent viscosity increases from $3 \mathrm{mPa}$ s to $20 \mathrm{mPa}$ s between low and high permeabilities. By analogy with viscosity variations with shear in a Couette cell, we may denote this as permeability "thickening". These results show a clear advance for oil recovery as it shows a higher viscosity in high permeability zones.

In application the aim is to demonstrate the selective retardation effects of SIS as a function of permeability. The fluid velocity in the high permeable zones $\kappa_{\mathrm{hi}}$ needs to be slowed down relative to the fluid velocity in the low permeable zones $\kappa_{\mathrm{lo}}$. In order to examine to what extent SIS additives selectively retard flow across

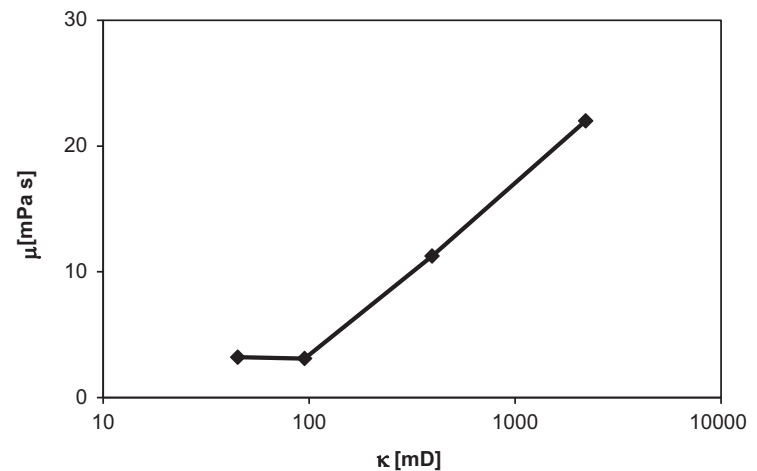

Fig. 5. Apparent viscosity as a function of permeability for four sintered glass cores (Table 1). The injected solution was $1.5 \mathrm{mM}$ equimolar in CTAB and NaSal.

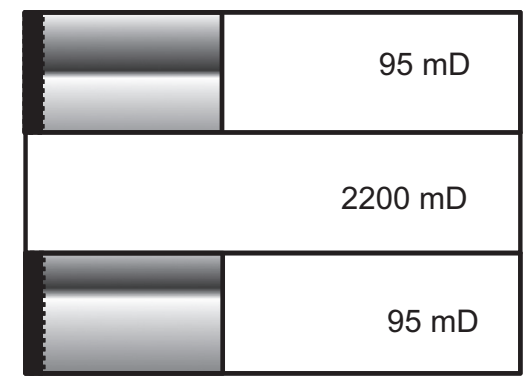

Fig. 6. Area swept for a reservoir section consisting of a high permeability streak sandwiched between two low permeability ones. When brine has swept the high permeability streak then only the solid filled region in the low permeability region has been filled. When $1.5 \mathrm{mM}$ equimolar in CTAB and NaSal is used the additional shaded grey area of the low permeability regions are swept.

different permeability cores, the Darcy velocity in experiments with SIS $(u)$ and brine base fluid $\left(u_{0}\right)$ are compared for each permeability. A parameter for retardation is then

$\delta=\frac{u_{0}-u}{u_{0}}=1-\frac{\mu_{0}}{R}$

At $100 \mathrm{mbar} / \mathrm{cm}$, then at low permeability the retardation is typically around $65 \%$, however this rises to $97 \%$ at higher permeabilities. This can be quantified for our original problem, i.e. channelling caused by heterogeneous permeability distribution in a reservoir. For demonstration consider three layers of two different permeabilities stacked on top of each other. The high permeability layer is placed in between the low permeability layers, which is visualised in Fig. 6 for $95 \mathrm{mD}$ and $2200 \mathrm{mD}$. Fluid in a brine waterflooding operation acquires a high velocity in the $2200 \mathrm{mD}$ layer compared to the lower velocity in the $95 \mathrm{mD}$ layer. Ultimately this results in water breakthrough at the producer well. The high permeable layer - $2200 \mathrm{mD}$ - is swept completely by brine, while the low permeable layers are only penetrated to a very limited extent (Fig. 6 solid fill). A significant amount of oil would still be trapped in the low permeability layers.

If now additivated brine ( $1.5 \mathrm{mM}$ SIS in brine) is used in the waterflooding operation, fluid is retarded selectively as demonstrated in the previous section. The fluid in the high permeable layer is slowed down to a greater extent than in the low permeability layer. This yields an additional absolute difference of $36 \%$ sweep area which is visualised in Fig. 6 (graded shading). This behaviour is the consequence of the demonstrated permeability "thickening". It is as yet unclear whether this behaviour is non-monotonic as has been observed in Couette cells. The question is whether permeability "thinning" would be observed at even higher permeability. In the current tests it was not observed 
in core samples which fall within the range of permeabilities interesting for oil recovery. At higher permeabilities we enter the regime of flow in microfractures - and this is an aspect currently under study.

Note that the pressure gradients used in this study are still considerably above those found in real oil recovery operations. Experiments aimed to derive SIS performance at very low pressure gradients are ongoing. The concentration of both CTAB and NaSal can be varied, to influence the sweep performance of SIS in oil recovery operations. A factor here is the behaviour of SIS solutions on contacting oil. It has already been demonstrated that highly aromatic crudes have a higher up-take of CTAB (Smeets and Golombok, 2010). In the presence of oil, the enhanced rheology may be lost (Samuel et al., 1999) however this behaviour is by no means a "show stopper" considering that we only desire viscous retardation in high water cut regions and normal brine viscosity is acceptable at high oil cuts.

\section{Conclusion}

Viscoelastic surfactants show increased resistance to flow (apparent viscosity) as a function of bulk permeability. In Couette flow, increasing viscosity as a function of varying shear rate is called shear thickening. By analogy we may consider our observations to correspond to permeability thickening - although it is understood that the permeability is fixed and it is the apparent viscosity which increases. For the range of permeabilities applicable to oil reservoirs, the apparent viscosities observed at high permeabilities are around 10 times that of the low permeability range. The flow is thus selectively retarded in high permeability regions. As a result of this, up to ca. 36\% extra volume of an oil reservoir can be swept.

This paper illustrated only the principle of application. There is a whole range of tuning and concentration variation possibilities that have yet to be explored. Primary among these are the effects of different total dissolved solids and the resulting salinity on viscoelastic response. The effect of temperature and the ability to maintain the desired effects at reservoir conditions are also important. The response also needs to be tuned for water/oil mixtures. Application is envisaged only after following a considerable period of water flooding. In this respect selective retardation should be maximised in regions of high relative water content but should be minimised when contact oil displacement occurs. Finally this demonstration took place on cores of only $40 \mathrm{~mm}$ length - not sufficiently large for significant spatial permeability variation. It is clear how the effect works in a layered system. This however is highly idealised and the behaviour where there is connectivity in three dimensions is the subject of current study. This is not expected to give a problem as there is always a path of minimum resistance between injector and producer and this study has shown that that is precisely where our method would retard the flow as desired for better profile conformance.

\section{References}

Awang, M., Japor, A., Sandeep, Dzulkarnain, I., 2012. Wormlike Micelles for Mobility Control in EOR. SPE Paper 155059.

Cheung, P., Dubash, N., Shen, A.Q., 2012. Local micelle concentration fluctuations in microfluidic flows and its relation to a flow-induced structured phase (FISP). Soft Matter 8, 2304

Cressely, R., Hartmann, V., 1998. Rheological behaviour and shear thickening exhibited by aqueous CTAB micellar solutions. Eur. Phys. J. B 6, 57.

Delshad, M., Kim, D.H., Magbagbeola, O.A., Huh, C., Pope, A., Tarahhorm, F., 2008 Mechanistic Interpretation and Utilization of Viscoelastic Behavior of Polymer Solutions for Improved Polymer Flood Efficiency. SPE 113620. SPE. Tulsa, OK.

Dowd, W.T., 1974. Secondary and Tertiary Oil Recovery Processes. Interstate oil. Oklahoma City.

Ezrahi, S., Tuval, E., Aserin, A., 2006. Properties, main applications and perspectives of worm micelles. Adv. Colloid Interface Sci. 128-130, 77.

Golombok, M., Crane, C., Ineke, E., Harris, J., Welling, M., 2008. Novel additives to retard permeable flow. Exp. Therm. Fluid Sci. 32, 1499.

Gonzalez, J.M., Miller, A.J., Torres, M.F., Saez, A.E., 2005. The role of shear and elongation in the flow of solutions of semi-flexible polymers through porous media. Rheol. Acta 44, 396.

Howard, S.C., Craig, V.S.J., 2009. Adsorption of the cationic surfactant cetyltrimethylammonium bromide to silica in the presence of sodium salicylate: surface excess and kinetics. Langmuir 25 (22), 13015.

Jones, W.M., 1980. Polymer additives in reservoir flooding for oil recovery: shear thinning or shear thickening? J. Phys. D 13, L87.

Moss, G.R., Rothstein, J.P., 2010. Flow of wormlike micelle solutions through a periodic array of cylinders. J. Non-Newtonian Fluid Mech. 165, 1.

Rojas, M.R., Mueller, A.J., Saez, A.E., 2008. Shear rheology and porous media flow of wormlike micelle solutions formed by mixtures of surfactants of opposite charge 221, 326J. Colloid Interface Sci. 221, 326.

Samuel, M.M., Card, R.J., Nelson, E.B., Brown, J.E., Vinod, P.S., Temple, H.L., Qu, Q. Fu, D.K., 1999. Polymer-free fluid for fracturing applications. SPE Drill Complet. 14 (4), 240.

Siriwatwechakul, W., 2005. Viscoelastic Rodlike Surfactant Micelles: Rheology and flow Through Porous Media. Princeton University. (Ph.D. thesis).

Smeets, M., Golombok, M., 2010. Application of shear induced structure materials for brine flooding in sandstone oil reservoirs. J. Pet. Sci. Eng. 72, 270.

Spain, D., Troost, S., Golombok, M., 2009. Shear induced structure additives and nonlinear pressure drop effects in permeable flow. J. Colloid Interface Sci. 338, 261.

Wang, S.-Q., Hu, Y., Jamieson, A.M., 1994. Formation of nonequilibrium micelles in shear and elongational flow. In: Proceedings of the Structure and Flow in Surfactant Solutions, ACS Symposium Series 578. Washington.

Yamamoto, T., Hashimoto, T., Yamashita, A., 2008. Flow analysis for wormlike micellar solutions in an axisymmetric capillary channel. Rheol. Acta 47, 963. 